\title{
Baltic Sea Action Plan process: co-production of science and policy
}

\author{
R. Aps, G. Martin \& O. Roots \\ Estonian Marine Institute, University of Tartu, Estonia
}

\begin{abstract}
Baltic Marine Environment Protection Commission (HELCOM) works as an environmental policy maker for the Baltic Sea area by developing common environmental objectives and actions. HELCOM Ministerial Meeting held in November 2007 in Krakow (Poland), adopted an ambitious Baltic Sea Action Plan to substantially reduce pollution to the Baltic Sea and restore its good ecological status by 2021. According to the hazardous substances segment of the HELCOM Baltic Sea Action Plan the overall goal is to achieve a Baltic Sea with life undisturbed by hazardous substances. The goal is described by four ecological objectives: 1) concentrations of hazardous substances close to natural levels, 2) all fish safe to eat, 3) healthy wildlife, and 4) radioactivity at preChernobyl level. In order to make the ecological objectives operational, the indicators with targets, reflecting good ecological and environmental status of the Baltic marine environment, have been agreed. The history of HELCOM activities demonstrates that the nominally scientific assessments of the Baltic environmental risks have helped to underpin the legitimacy of claims about the need for new Baltic regional political co-operation. At the same time, the Baltic regional political co-operation has proved necessary to support the legitimacy and credibility of scientific assessments of the Baltic environmental risks.
\end{abstract}

Keywords: Baltic Sea Action Plan, marine environment protection, coproduction of science and policy.

\section{Introduction}

Baltic Marine Environment Protection Commission - also known as HELCOM is the governing body of the "Convention on the Protection of the Marine Environment of the Baltic Sea Area," more usually known as the Helsinki 
Convention (1974, entered into force in 1980; 1992, entered into force in 2000). The present Contracting Parties to HELCOM are Denmark, Estonia, European Community, Finland, Germany, Latvia, Lithuania, Poland, Russia and Sweden. HELCOM works to protect the marine environment of the Baltic Sea from all sources of pollution and to ensure the safety of navigation in the region.

The scientific assessment process within International Council for the Exploration of the Sea (ICES) is generally considered as having been successful in generating, synthesising, and disseminating scientific knowledge. The ICES advisory process could be seen as an example of efficient co-production of science and policy. Within the context of Helsinki Commission there has been a successful division and co-ordination of work between science and policy providing a forum which simultaneously co-produced a scientific knowledge framework and a framework for policy making.

According to HELCOM Ministerial Declaration (HELCOM Bremen Declaration) adopted in Bremen in 2003, the priority issues for HELCOM in the near future will be an ecosystem approach including nature conservation and biodiversity, joint monitoring and assessment, maritime safety and shipping including response activities as well as eutrophication and hazardous substances of relevance for the Baltic Sea [1]. Furthermore, the HELCOM and the OSPAR (OSPAR Commission for the Protection of the Marine Environment of the North East Atlantic) jointly adopted their common vision of an ecosystem approach to managing human activities impacting on the marine environment (an "ecosystem approach") during the First Joint Ministerial Meeting of the HELCOM and OSPAR in Bremen in 2003. It was underlined that better integration of environmental objectives with economic and social goals is a basic requirement for advancing and strengthening these three interdependent and mutually reinforcing pillars of sustainable development.

The literature within the field of science studies offers a dynamic image of the relationship between science and policy [2-6]. The term co-production is used to refer to processes that connect the production of knowledge with the organization of policy-making where science and policy together define problems and create knowledge [7, 8].

Policy relevance of the research results is believed to be based on the process of co-production - the concept well presented in the collection of essays by some of the leading scholars in the field [4] - that is showing how scientific knowledge both embeds and is embedded in social identities, institutions, representations and discourses. Co-production of science and policy is considered to be an important element in production of usable science [5]. Usable science refers to the degree that the science produced through coproduction process results in knowledge that meets constituent needs. Authors argue that the knowledge produced should be understandable to users, available at the times and places it is needed, and accessible through the media available to the user community.

This paper examines the co-production of science and policy by actively involving the stakeholders in a process of development and implementation of the HELCOM Baltic Sea Action Plan. 


\section{Science-policy interface}

International Council for the Exploration of the Sea (ICES) was established in 1902 as an intergovernmental organization with the aim: 1) to promote and encourage research and investigations for the study of the sea particularly related to the living resources thereof, 2) to draw up programmes required for this purpose and to organise, in agreement with the Contracting Parties, such research and investigations as may appear necessary, and 3) to publish or otherwise disseminate the results of research and investigations carried out under its auspices or to encourage the publication thereof.

According to ICES Strategic Plan [9] the Mission of ICES - to advance the scientific capacity to give advice on human activities affecting, and affected by, marine ecosystems - clearly embraces the need for advice as the ultimate driving force behind ICES, while at the same time recognizing that advancing scientific capability is the key to fulfilling this need. In reality, it is the scientists, from government, academia, and other sectors from ICES Member Countries and elsewhere, who produce the advice.

The goals of ICES Strategic Plan are as follows: 1) plan and implement a programme of science in partnership with Member Countries to deliver the needs of customers and stakeholders, 2) establish effective mechanisms of collaboration within ICES and with other organizations to deliver and add value to ICES Science and Advisory programmes, 3) plan and implement a programme to deliver the advice that decisionmakers need in partnership with Member Countries and client commissions, 4) develop a comprehensive strategy to manage and disseminate marine data for the ICES Area in support of the Science and Advisory programmes, and 5) build understanding of ICES science and marine issues through a programme of communication within ICES and with the wider public. ICES have evolved considerably in the last few years with respect to the ways it supports the management and policy formulation.

Memorandum of Understanding between the Helsinki Commission and the ICES [10] is representing inter alia the following understanding: 1) ICES will provide to HELCOM scientific information and advice, which is independent and free from political influence, 2) ICES and HELCOM will consult regularly on ways in which co-operation between them can be further improved and extended including, as appropriate, common meetings of subsidiary bodies or the establishment of joint subsidiary bodies, which would report to both organizations, 3) ICES will provide HELCOM with an annual report containing scientific information and provided at appropriate times during the year, while any other relevant reports published by ICES will be made available to HELCOM. ICES currently holds also a contract with HELCOM for managing all "at sea" observations collected as part of the HELCOM's COMBINE programme. 


\section{Baltic co-operative research}

The history of HELCOM activities demonstrates that the nominally scientific assessments of the Baltic environmental risks have helped to underpin the legitimacy of claims about the need for new Baltic regional political cooperation. At the same time, the Baltic regional political co-operation has proved necessary to support the legitimacy and credibility of scientific assessments of the Baltic environmental risks.

Importance of the regional cooperation in strengthening the knowledge base for cost-efficient implementation of the Baltic Sea Action Plan was underlined by the Fourth HELCOM Stakeholder Conference (Helsinki, 4 March 2009). The ERA-NET project of the EU Sixth Framework Program "BONUS for the Baltic Sea Science - Network of Funding Agencies" [11] was aiming at building up a network of funding agencies in the Baltic Sea countries and creating conditions for a Joint Baltic Sea Research Program, called BONUS-169.

The aim of the BONUS-169 is to enhance integration and cooperation on research and development related to the Baltic Sea and to contribute to closing the gaps in research in support of the implementation of the HELCOM Baltic Sea Action Plan. Different research themes within BONUS-169 are chosen with the aim to match the HELCOM Baltic Sea Action Plan priorities related to the status of the marine environment of the Baltic Sea. It is expected that the policy relevance of the research financed within BONUS-169 will be further strengthened through practical dialogue with HELCOM working groups and experts.

Three projects co-financed by the Baltic Sea Region Program 2007-2013 (BSRP) [11], namely BRISK, COHIBA and IBAM can be considered as an example of HELCOM activities supported by the EU funds to implement the Baltic Sea Action Plan. The aim of the project "Sub-regional risk of spill of oil and hazardous substances in the Baltic Sea" (BRISK) is to substantially contribute to the HELCOM countries' ability to efficiently respond to major pollution spills, and to deliver information for decision-makers about the resources needed for efficient response to major pollution at sea.

It is expected that the project "Control of hazardous substances in the Baltic Sea region" (COHIBA) will contribute to the HELCOM thematic assessment on hazardous substances, and more importantly to the development of national management programs to control hazardous substances required under the Baltic Sea Action Plan and other legislative frameworks. The project will identify the sources of 11 priority hazardous substances, and will analyze their flow patterns from production, releases and inputs to the Baltic Sea.

The main objective of the project "Integrated Bayesian risk analysis of ecosystem management - Gulf of Finland as a case study" (IBAM) is to create an environmental decision model for the Gulf of Finland. The model integrates risk management of five themes: fisheries, eutrophication, oil spills, dioxin risks related to the consumption of herring, and the climate change. Modelling results will also include uncertainty in human management responses, and will be used to rank decision options in an interdisciplinary and multi-objective context. The 
project will enable more effective learning in science by providing systematic tools and probabilistic databases of state of the nature to be used as prior information for future studies.

The Fourth HELCOM Stakeholder Conference ((Helsinki, 4 March 2009) suggested that the scientific results still need to be better communicated from the science community to the decision makers and better taken into account in decision making and not only economic but also social knowledge should be utilized.

\section{Action plan based on ecological objectives}

Development of Ecological Quality Objectives within HELCOM for the Baltic Sea can be considered as an important part of the process of regional implementation of the ecosystem approach and the European Marine Strategy. Ecological Quality Objectives (EcoQOs), associated indicators and target levels of these indicators are central tools in implementing the ecosystem approach to which HELCOM has committed itself by the Bremen Ministerial Declaration of 2003 [11].

The EcoQOs have been developed by the HELCOM project "Development of Ecological Quality Objectives within the Baltic Sea (HELCOM EcoQO)" in 2004-2005, and under the theme "Hazardous Substances" they are listed as follows: 1) concentrations of hazardous substances in the Baltic Sea near background values for naturally occurring substances and close to zero for manmade substances, 2) no illegal oil spills, 3) all fish caught in the Baltic Sea should be suitable for human consumption, 4) toxic substances shall not cause sub-lethal, intergenerational or transgenic effects to the health of marine organisms (e.g. reproductive disturbances), and 4) attain pre-Chernobyl concentrations of man-made radioactivity in the Baltic Sea ecosystem causing risk neither to human nor the natural systems [12].

According to Article 5 of the Helsinki Convention the Contracting Parties undertake to prevent and eliminate pollution of the marine environment of the Baltic Sea Area caused by harmful substances from all sources, according to the provisions of the Convention. Annex I to the Helsinki Convention lists 1) criteria on the allocation of substances, 2) priority groups of harmful substances, and 3) banned substances including the pesticides. Contaminants that are ecologically harmful are also referred to as pollutants or hazardous substances. Hazardous substances in the Baltic Sea include 1) substances that do not occur naturally in the environment, such as PCBs, DDTs, dioxins, TBT, nonylphenolethoxylates (NP/NPE), short-chained chlorinated paraffins (SCCP), brominated flame retardants (PBDEs) and certain nitromusks, and 2) substances occurring at concentrations exceeding natural levels, including heavy metals like lead, copper, cadmium and mercury. The agreed goal of HELCOM on Hazardous substances Baltic Sea undisturbed by hazardous substances is described by agreed ecological objectives [13]. 


\section{Land-based pollution}

The Baltic environmental studies show that most of the pollution in the Baltic Sea originates from sources on land while the Baltic has for centuries been used as a huge natural treatment plant for the wastes generated around its catchment area, which is nowadays home to almost 85 million people, and characterized by intensive industrial and agricultural development [14]. The HELCOM Landbased Pollution Group (HELCOM LAND) is responsible for reducing pollution from all sources on land within the Baltic Seas catchment area by identifying point and diffuse sources of land-based pollution of nutrients and hazardous substances, and by proposing suitable actions in order to reduce these emissions and discharges. The objective of HELCOM LAND is to reduce inputs of nutrients, especially from diffuse sources such as agriculture and transport and to pursue the cessation target for discharges, emissions and losses of hazardous substance by 2020 .

\section{Environmentally friendly maritime activities}

The Maritime Group of the Helsinki Commission (HELCOM MARITIME) works to prevent any pollution from ships - including deliberate operational discharges as well as accidental pollution. HELCOM MARITIME cooperates with International Maritime Organization (IMO) to ensure that international measures are properly applied and implemented in the Baltic, and with the Regional Seas Program (RSP) and the Global Program of Action for the Protection of the Marine Environment from Land-Based Activities (GPA) under UNEP to address the problem of marine litter both at regional as well as global level [15].

Article 8 of the Helsinki Convention suggests that the Contracting Parties shall develop and apply uniform requirements for the provision of reception facilities for ship-generated wastes, taking into account, inter alia, the special needs of passenger ships operating in the Baltic Sea Area. Noting the increasing concern of harmful effects of marine litter in the environment of the Baltic Sea, the HELCOM Recommendation 29/2 proposes that all the Baltic Sea States should support beach litter monitoring activities and beach clean-up campaigns and should cooperate with local authorities and NGOs in this matter. This resolution recommends further that all the Baltic Sea States, in cooperation with local authorities, raise public awareness on negative effects of marine litter on coastal and sea ecosystems, and keep the issue of marine litter under regular review to make sure that the quantities and properties of marine litter do not cause harm to the coastal and marine environment.

HELCOM suggests also that the Governments of the Contracting Parties implement the HELCOM Recommendation 28E/10 and the attached Guidelines in order to establish of a harmonized "no-special-fee" system for the operation of reception facilities in their ports for ship-generated wastes, and that the litter caught in fishing nets be covered by the "no-special-fee" system. In the context of this Recommendation the "no-special-fee" system is defined as a charging 
system where the cost of reception, handling and disposal of ship-generated wastes, originating from the normal operation of the ship, as well as of marine litter caught in fishing nets, is included in the harbour fee or otherwise charged to the ship irrespective of whether wastes are delivered or not.

Forecasts indicate that by 2015 more than 130 million tons of oil will be transported on the Baltic Sea every year, and this could raise the risk of a large oil-spill involving over 10,000 tons of oil by $35 \%$ for the whole of the Baltic Sea, and $100 \%$ for the Gulf of Finland [16]. HELCOM RESPONSE works 1) to ensure swift national and international response to maritime pollution incidents, 2) to ensure that in case of an accident the right equipment is available and routines are in place to respond immediately in co-operation with neighboring states, 3) to analyze developments in maritime transportation around the Baltic and investigate possible impacts on international cooperation with regard to pollution response, 4) to coordinate the aerial surveillance of maritime shipping routes to provide a complete picture of sea-based pollution around the Baltic, and 5) to help identify suspected polluters. The Group continuously updates and reviews the HELCOM Response Manuals - Volume 1 (Oil) and Volume 2 (Chemicals).

\section{Marine Strategy Framework Directive}

The aim of the European Union's Marine Strategy Framework Directive (adopted in June 2008) is to protect more effectively the marine environment across Europe [17]. The Marine Strategy Framework Directive establishes European Marine Regions on the basis of geographical and environmental criteria. Furthermore, the Member States - cooperating with other Member States and non-EU countries within a marine region - are required to develop strategies for their marine waters. It is forseen that the marine strategies to be developed by each Member State must contain a definition of "good environmental status" at regional level and the establishment of clear environmental targets and monitoring programs.

The concept of the HELCOM Baltic Sea Action Plan has already been widely discussed and supported by politicians at various forums. The European Community has emphasized that the plan is instrumental to the successful implementation of the EU Marine Strategy Framework Directive in the region, and it has been considered as a potential pilot project for European seas in the context of the EU Marine Strategy Framework Directive [18]. The overarching HELCOM Baltic Sea Action Plan to considerably reduce pollution to the Baltic Sea and restore its good ecological status by 2021 has received the European Regional Champions Award 2007 in the environment category.

\section{Maritime Spatial Planning}

It is now widely recognized that the fast growth in maritime activities such as maritime transport, port development, aquaculture, offshore drilling and tourism, combined with emerging and potentially new uses of the sea such as offshore 
renewable energy, blue biotech and underwater technologies, is increasing the pressure on already limited marine space.

According to the European Commission's Roadmap [19] the Maritime Spatial Planning (MSP) is seen as a key instrument for the EU Integrated Maritime Policy implementation that helps public authorities and stakeholders to coordinate their action and optimises the use of marine space to benefit economic development and the marine environment.

MSP has to be based on sound information and scientific knowledge while the planning needs are expected to evolve with knowledge (adaptive management). With aim to further develop the necessary scientific knowledge the Commission has started several scientific and data gathering tools that will assist MSP in this process (European Marine Observation and Data Network (EMODNET), an integrated database for maritime socio-economic statistics (currently under development by ESTAT), the European Atlas of the Seas and the Global Monitoring for Environment and Security -"Kopernikus").

The EU INTERREG IVA project BaltSeaPlan can be seen as one the major EU initiatives in the field of maritime spatial planning in the coming years [20]. With 14 partners from seven Baltic countries, the project will provide key input into the realization of the EU Maritime Policy, HELCOM Baltic Sea Action Plan and the VASAB Gdańsk Declaration. It is planned that with a learning-by-doing approach BaltSeaPlan will overcome the lack of relevant legislation in most Baltic Sea Region countries. Seven important Baltic areas were chosen for pilot maritime spatial plans, among them the Pomeranian Bight, Gulf of Gdańsk or the Middle Bank area between Poland and Sweden, Saaremaa-Hiiumaa Island and Pärnu Bay in Estonia.

In a course of broad scale stocktaking of maritime uses that will be carried out in each pilot area the additional information will be collected with application of newest tools and methods, such as sea-bed modeling and climate change scenarios. It is planned to harmonize all data according to requirements of the EC INSPIRE directive and to compile data in a joint database. It is expected also that BaltSeaPlan will provide key input into National Maritime Strategies as required by the EU Blue Book on Future Maritime Policy. In 2011 a common spatial development vision for the Baltic Sea will be produced as a synergy of the national visions and plans of all Baltic Sea Region countries.

\section{Stakeholder participation}

Kick-off Stakeholder Conference on the development of the HELCOM Baltic Sea Action Plan was held on 7 March 2006 in Helsinki, Finland. The Conference addressed the aim and timing of the HELCOM Baltic Sea Action Plan, and the state of marine environment. Participants focused on the proposed objectives for the main environmental issues: eutrophication, hazardous substances, biodiversity and shipping, as well as general comments and presentations by high-level politicians. The European Commission strongly backed the HELCOM Baltic Sea Action Plan and expressed intention to take an active part in its development. 
The 2nd Stakeholder Conference on the development of the HELCOM Baltic Sea Action Plan was held on 6 March 2007 in Helsinki, Finland. The major aim of the Conference was to review the plan's outline and the proposed set of actions for each of the four segments of the plan dealing with eutrophication, pollution involving hazardous substances, maritime safety and accident response capacity, habitat destruction and the decline in biodiversity. At the conference, HELCOM also presented four drafts of thematic assessment reports on eutrophication, biodiversity, maritime activities, and hazardous substances, which was intended to serve as background information to the action plan.

The 3rd Stakeholder Conference on the HELCOM Baltic Sea Action Plan (4 March 2008, Helsinki, Finland) focused on three themes: broad-scale maritime spatial planning, financing the implementation of the Action Plan and how to prepare successful projects to ensure/increase the investments for marine environment protection. In particular, HELCOM Contracting Parties committed themselves to develop by 2010, as well as test, apply and evaluate by 2012, in co-operation with other relevant international bodies, broad-scale, cross-sectoral, maritime spatial planning principles based on the Ecosystem Approach.

The latest 4th HELCOM Stakeholder Conference (3 March 2009, Helsinki, Finland) was focused on the theme "Building blocks for a cost-effective implementation of the HELCOM Baltic Sea Action Plan". The Conference considered the Baltic Sea Action Plan instrumental in implementing the various pieces of EU legislation and strategies relevant from the point of view of protecting the marine environment, especially the Marine Strategy Framework Directive and the upcoming EU Baltic Sea Region Strategy. It was considered important to involve the International Financial Institutions and the private sector in the implementation of the HELCOM Baltic Sea Action Plan and to get to know their requirements for providing financing support.

\section{Achievements}

The HELCOM Baltic Sea Action Plan Implementation Group (BSAP IG) is holding its regular meetings to review the status of ongoing activities aimed at restoring the good ecological status of the Baltic marine environment by 2021 . The major focus of these meetings is on the implementation of the eutrophication and hazardous substances segments of the action plan, which foresee measures to reduce excessive inputs of nitrogen and phosphorus that are responsible for the degradation of the sea, as well as prevent pollution by hazardous substances. The "polluter pays" principle is implemented by HELCOM as the economic basis for the control of environmentally harmful activities, emphasizing the importance of responsibility by forcing polluters to pay for the true costs of their activities.

The three decades of Helsinki Commission's work with aim to improve the Baltic marine environment has resulted in 1) lower discharges of organic pollutants and nutrients from point-sources, 2) a 20-25\% overall reduction in the emissions of oxygen-consuming substances (BOD) from the 132 originally identified hot spots since the early 1990s, with about 50 hot spots deleted from 
the list, 3) fewer beaches closed for bathing, thanks to improvements in the treatment of industrial and municipal wastewater, 4) significant reductions in atmospheric nitrogen deposition, 5) dramatic reductions in emissions of organohalogen compounds such as toxic dioxins and furans, 6) national regulations banning hazardous substances like PCB and DDT, 7) the recovery of seal and white-tailed eagle populations, 8) better special legislation to prevent the pollution of the Baltic Sea by shipping, developed together with the International Maritime Organization (IMO) if just to list some more important achievements [21].

\section{Conclusions}

The scientific assessment process within ICES is generally seen as having been successful in generating, synthesising, and disseminating scientific knowledge on the Baltic ecosystem while the ICES advisory process could be seen as an example of efficient co-production of science and policy. Within the context of Helsinki Commission there has been a successful division and co-ordination of work between science and policy providing a forum which simultaneously coproduced a scientific knowledge framework and a framework for policy making.

HELCOM works as an environmental policy maker for the Baltic Sea area by developing common environmental objectives and actions. The history of HELCOM activities demonstrates that the nominally scientific assessments of the Baltic environmental risks have helped to underpin the legitimacy of claims about the need for new Baltic regional political cooperation. At the same time, the Baltic regional political cooperation has proved necessary to support the legitimacy and credibility of scientific assessments of the Baltic environmental risks.

\section{Acknowledgements}

The study was supported by the Estonian target financing program SF0180104s08 and by the Baltic Organisations Network for Funding Science EEIG (BONUS) Project IBAM “Integrated Bayesian risk analysis of ecosystem management - Gulf of Finland as a case study".

\section{References}

[1] HELCOM. Towards an Ecosystem Approach to the Management of Human Activities. First Joint Ministerial Meeting of the HELSINKI AND OSPAR Commissions. BREMEN, 25-26 June 2003. http://www.helcom.fi /ministerial_declarations/en_GB/ospardeclaration/. 2003.

[2] Miller, C. Hybrid management: boundary organizations, science policy, and environmental governance in the climate regime. Science, Technology \& Human Values, Vol. 26 (4), pp. 478-500. 2001. 
[3] Miller, C. Democratization, International Knowledge Institutions, and Global Governance. Governance: An International Journal of Policy, Administration, and Institutions, Vol. 20(2), pp. 325-357. 2007.

[4] Jasanoff, S. (Ed.). States of knowledge: The co-production of science and social order. London: Routledge, 317 p. 2004.

[5] Lemos, M.C., Morehouse B.J. The co-production of science and policy in integrated climate assessments. Global Environmental Change, 15, pp. 57-68. 2005.

[6] Lövbrand, E. Pure science or policy involvement? Ambiguous boundarywork for Swedish carbon cycle science. Environmental Science \& Policy, 10, pp. 39 - 47. 2007.

[7] Tuinstra, W. European air pollution assessments: co-production of science and policy. Int. Environ. Agreements, 8, pp. 35-49. 2008.

[8] Aps, R., Fetissov, M., Kell, L., Lassen H. Baltic Sea Regional Advisory Council as a hybrid management framework for sustainable fisheries. Ecosystems and Sustainable Development VII (Eds. C.A. Brebbia, E. Tiezzi). WITpress, pp. 163-172, 2009.

[9] ICES A vision worth sharing. ICES Strategic Plan. http://www.ices.dk /iceswork/AVisionWorthSharing2008.pdf. 2009.

[10] ICES 2009. Memorandum of Understanding between the Helsinki Commission and the International Council for the Exploration of the Sea. Online. http://www.ices.dk/indexfla.asp. 1999.

[11] Baltic Organizations Network for Funding Science EEIG (BONUS) http://www.bonusportal.org/

[12] HELCOM. Ecological Quality in the Baltic Sea. http://www.helcom.fi /environment2/ecoqo/en_GB/intro/. 2009.

[13] HELCOM. Towards a Baltic Sea Unaffected by Hazardous Substances. Background document for the HELCOM Ministerial Meeting 2007 elaborated by the HELCOM Secretariat. http://www.helcom.fi/stc /files/Krakow2007/HazardousSubstances_MM2007.pdf . 2007.

[14] HELCOM LAND. Land-based Pollution Group (HELCOM LAND). http://www.helcom.fi/groups/LAND/en_GB/main/. 2009.

[15] HELCOM MARITIME. Maritime Group (HELCOM MARITIME). http://www.helcom.fi/groups/maritime/en_GB/main/. 2009.

[16] HELCOM RESPONSE. Response Group (HELCOM RESPONSE). http://www.helcom.fi/groups/response/en_GB/main/

[17] EU. Directive 2008/56/EC of the European Parliament and of the Council of 17 June 2008 establishing a framework for community action in the field of marine environmental policy (Marine Strategy Framework Directive).

http://eurlex.europa.eu/LexUriServ/LexUriServ.do?uri=OJ:L:2008:164:00 19:0040:EN:PDF. 2008.

[18] HELCOM. Activities 2007 - overview. HELCOM, Baltic Sea Environment Proceedings, 114, 96 p. 2007, http://www.helcom.fi/stc/files /Publications/Proceedings/bsep114.pdf. 
198 Management of Natural Resources, Sustainable Development and Ecological Hazards II

[19] European Commission. Roadmap for Maritime Spatial Planning: Achieving Common Principles in the EU. Communication from the Commission. Brussels, 25 November 2008, COM(2008) 791, 12 p. 2008.

[20] BaltSeaPlan. BaltSeaPlan Project - Introducing Maritime Spatial Planning in the Baltic Sea. http://www.baltseaplan.eu/

[21] HELCOM. HELCOM Indicator Fact Sheets for 2008. http://www.helcom.fi/environment2/ifs/ifs2008/en_GB/cover/.2008. 